\title{
Can We diagnose Keratoconus by evaluating Tear Sample?
}

\author{
${ }^{1}$ Burcu Nurözler Tabakcı, ${ }^{2}$ Aylin Kılıç, ${ }^{3}$ Mustafa Eliaçık
}

\begin{abstract}
Keratoconus (KC) is the most common corneal ectatic disorder characterized by asymmetric cone-shaped corneal protrusion. The pathophysiology of KC is still unclear. For many years, $\mathrm{KC}$ has been considered as a noninflammatory degenerative disease. However, several studies suggested that inflammatory mediators play a role in $\mathrm{KC}$ pathogenesis. Tear film contains various mediators that reflect ocular surface diseases. Monitoring the changes in tear composition can be used as a diagnostic tool. In this review, the adequacy of tear markers in the diagnosis of $\mathrm{KC}$ was discussed.
\end{abstract}

Keywords: Biomarkers, Keratoconus, Tear fluid.

How to cite this article: Tabakcı BN, Kılıç A, Eliaçık M. Can We diagnose Keratoconus by evaluating Tear Sample? Int J Kerat Ect Cor Dis 2018;7(1):31-34.

\section{Source of support: Nil}

Conflict of interest: None

\section{INTRODUCTION}

Keratoconus is the most common ectatic corneal disorder. It is characterized by asymmetric, progressive corneal thinning and protrusion, leading to irregular astigmatism and visual impairment. The prevalence of $\mathrm{KC}$ is 1:2000 in the population. The onset of KC characteristically occurs in early adolescence and it progresses until the third or fourth decade of life. ${ }^{1,2}$ The etiology of KC is not completely understood. Genetic, environmental, and biomechanical factors are thought to play a role in the pathogenesis. Atopy, ocular allergies, and eye rubbing are the proven risk factors for KC. For many years, $\mathrm{KC}$ has been considered as a noninflammatory disease. However, recent studies have suggested that inflammatory mediators are involved in KC pathogenesis. ${ }^{3}$

Clinical signs are well described, but vary according to the severity of the KC. It is difficult to diagnose $\mathrm{KC}$ with clinical signs in early stages. Corneal topography and tomography are important tools for diagnosis at

\footnotetext{
${ }^{1}$ Ophthalmologist, ${ }^{2,3}$ Associate Professor

${ }^{1-3}$ Department of Ophthalmology, Istanbul Medipol University Istanbul, Turkey

Corresponding Author: Burcu Nurözler Tabakcl, Ophthalmologist Department of Ophthalmology, Istanbul Medipol University Istanbul, Turkey, e-mail: burcunurtabakci@gmail.com
}

every stage of KC. Soft and rigid-gas permeable contact lenses (RGP CLs), collagen cross-linking, intracorneal ring segments, and keratoplasty are the treatment options for patients in different stages.

\section{Tear Film}

Tear film is a compound extracellular fluid that contains proteins/peptides, lipids, metabolites, and electrolytes with important functions to provide a healthy ocular surface. It is organized as a trilaminar structure consisting of an outer lipid layer, a middle aqueous layer, and an inner mucin layer. The lipid layer maintains a hydrophobic barrier and retards evaporation of the aqueous layer. The aqueous layer supplies oxygen and nutrients to the avascular corneal epithelium, washes away debris, provides antibacterial and antiviral defense, and regulates corneal and conjunctival cell function. The mucin layer is closest to the covers and converts the corneal epithelium from a hydrophobic layer to hydrophilic layer. ${ }^{4}$

Numerous studies have been conducted to understand the composition of tear film. The composition and function of tear fluid lipidome were analyzed using thin layer chromatographic, enzymatic, and mass spectrometric techniques. Rantamäki et $\mathrm{al}^{5}$ showed that the lipidome of the tear fluid is not similar to meibomian gland secretions and the polar lipids are the most common lipid species followed by cholesteryl esters and triglycerides.

It is difficult to detect tear metabolites because of the small amounts in the tears. Chen et $\mathrm{al}^{6}$ reported 60 metabolites including amino acids, amino alcohols, amino ketones, carbohydrates, carnitines, cyclic amines, nucleosides and nucleotides, peptides, phospholipids, purines, quaternary amines, and pyridoxal and tricarboxylic acids.

Predominant tear proteins like albumin, lysozyme, and lactoferrin are well known for their antimicrobial properties. Recent studies have focused on tear proteins extensively, and more than 1,500 proteins were defined in tear fluid. ${ }^{7-10}$ Zhou et al $^{7}$ have identified a comprehensive tear protein list which can be used as a reference list for biomarker search of ocular and systemic diseases.

\section{Biomarkers in Tear Fluid}

Biomarkers are the indicators of biological processes. They can be used as a tool for identifying diseases or 
monitoring pharmacologic responses in abnormal biological processes. ${ }^{11}$ Human body fluids are important sources for the disease-specific biomarkers. Tear fluid is an accessible source for biomarker researches. Samples can be obtained sufficiently by using two different noninvasive techniques—capillary tube and Schirmer strip. ${ }^{12}$ As tears contain numerous proteins and metabolites, proper storage of tear samples is essential for reliable results. Sitaramamma et $\mathrm{al}^{13}$ showed that total protein concentration of tears decreased significantly when the samples are kept at room temperature for 4 to 8 hours. They also concluded that tear samples could be stored up to 4 months at $-70^{\circ} \mathrm{C}$ without any change in protein composition.

Systemic and ocular diseases, such as diabetes mellitus, ${ }^{14}$ Sjogren's syndrome, ${ }^{15}$ glaucoma, ${ }^{16,17}$ dry eye ${ }^{18,19}$ thyroid-associated orbitopathy ${ }^{20}$ can alter the proteome patterns of tear fluid. Massingale et $\mathrm{al}^{21}$ showed that interleukin (IL)-1 $\beta$, IL-2, IL-4, IL-5, IL-6, IL-8, IL-10, interferon (IFN)- $\gamma$, tumor necrosis factor (TNF)- $\alpha$ were all significantly increased in the tears of dry eye patients as compared with normal controls. Decreased levels of lactoferrin, lysozyme, and secretory immunoglobulin $(\operatorname{sg} A)$ have been found to be associated with dry eye. ${ }^{8}$

\section{Biomarkers for KC}

Tear composition varies in ocular surface pathologies. Corneal ectasia in $\mathrm{KC}$ is associated with increased extracellular matrix disruption. Increased collagenase and gelatinase activities in cornea cultures and collagen degradation products in tears of KC have been reported. ${ }^{22,23}$ Matrix metalloproteinases (MMPs) are a family of endopeptidases that are synthesized by corneal epithelial and stromal cells. Physiologically, the main function of MMPs is tissue remodeling, but pathologically, they cause extracellular matrix degredation. ${ }^{24}$

Lema and Durán ${ }^{25}$ measured the tear concentrations of various cytokines (IL-4, IL-6, IL-10, and TNF- $\alpha$ ), cell adhesion molecules [intercellular adhesion molecule (ICAM)- 1 and vascular cell adhesion molecule (VCAM)1] and MMP-9 by enzyme-linked immunosorbent assay (ELISA). They showed increased levels of IL-6, TNF- $\alpha$, and MMP-9 in the tears of KC patients who had no clinical sign of inflammation and this overexpression was found to be related to the stage of KC. After this study, they investigated the effects of RGP CLs on tear composition and found that wearing RGP CLs induces overexpression of ICAM-1 and VCAM-1, in addition to proinflammatory cytokines (IL-6 and TNF- $\alpha$ ) in KC patients. ${ }^{26}$

Pannebaker et $\mathrm{al}^{27}$ reported the increased expression of MMP-1 in KC patients with and without RGP CL wear. No MMP-1 was found in the tears of healthy controls.
Jun et $\mathrm{al}^{28}$ investigated a wide range of inflammatory cytokines including IL-1b, IL-4, IL-6, IL-10, IL-12, IL-13, IL-17, IFN- $\gamma$, chemokine C-C motif ligand 5 (CCL5), and TNF- $\alpha$ in tear samples of KC patients and healthy controls using multiplex immuno-bead assays. Their measurements for IL- 6 and TNF- $\alpha$ were 5 to 10 times higher than the previously reported single ELISA measurements. After subtracting the effects of age and CL use, they determined significant decreases in IL-12, TNF- $\alpha$, and CCL5 in KC compared with control tear fluids. They concluded that use of different antibody-based assays and diversity in patient population may cause variation in cytokine levels.

In most cases, $\mathrm{KC}$ is initially unilateral. The fellow eye may develop KC or remain unchanged. A previous study revealed that some cytokines, such as IL-6 and TNF- $\alpha$ are overexpressed in the tears of both eyes of unilateral KC patients, but MMP-9 levels increased only in the $\mathrm{KC}$ eyes. ${ }^{29}$

The concentration changes of tear film proteins, such as cystatin, lipocalin-1, lipophilin, and phospholipase A2, have been reported in KC patients. Cystatins are proteinase inhibitors. Decreased levels of cystatins in KC patients' tears are associated with the degradation of tear proteins, and that explains the decrease of tears' total protein concentration. Increased lipid peroxidation leads to elevated lipocalin-1 levels in the tears of KC patients. Decreased levels of lipophilin and phospholipase A2 can alter the tears' stability of KC patients. Increased levels of albumin in tears from $\mathrm{KC}$ patients indicate albumin exudation from conjunctival vessels. ${ }^{30}$

Another study showed that the amount of total protein and the concentrations of major tear proteins including lactoferrin and secretory IgA were significantly decreased in KC tears. These differences were not related to CL wear, age, gender, or atopy of subjects. ${ }^{31}$ Similarly, decreased levels of lactoferrin, lysozyme, and sIgA have been reported in tears after photorefractive keratometry. ${ }^{32}$ Secreted frizzled-related proteins (SFRPs) inhibit Wnt signaling pathways. You et $\mathrm{al}^{33}$ showed that, tear SFRP1 was significantly decreased in $\mathrm{KC}$, compared with healthy subjects but they concluded that tear SFRP1 levels alone do not provide an obvious biomarker for KC.

Balasubramanian et $\mathrm{al}^{34}$ showed that the proteolytic activity in the tear of $\mathrm{KC}$ patients is 1.9 times higher and the total tear protein level was significantly reduced compared with healthy controls or patients who had undergone corneal collagen cross-linking. Significantly increased expressions of MMP-1, MMP-3, MMP-7, MMP-13, IL-4, IL-5, IL-6, IL-8, and TNF- $\alpha$, and TNF- $\beta$ have been demonstrated in tear of $\mathrm{KC}$. The only cytokine that significantly increased in tears of KC is IL-6, compared with the collagen cross-linked group. The expression of 
Can We diagnose Keratoconus by evaluating Tear Sample?

TNF- $\alpha$ was significantly increased in the cross-linked group compared with the healthy subjects. The activity of tear gelatinases and collagenases in the collagen crosslinked group was not significantly different compared with either KC or healthy subjects.

Sorkhabi et $\mathrm{al}^{35}$ showed that patients with $\mathrm{KC}$ had significantly higher levels of the proinflammatory markers (IL-6, IL-1b, and IFN- $\gamma$ ), whereas significantly lower levels of the anti-inflammatory marker (IL-10) compared with controls.

Lysyl oxidase (LOX) is responsible for the formation of lysine-derived cross-links in extracellular matrix proteins. There are two contradictory reports in literature, suggesting reductions and increases of LOX expression in $\mathrm{KC}$ corneas. Shetty et $\mathrm{al}^{36}$ demonstrated that the enzymatic activity of LOX in tears from KC patients is significantly reduced compared with healthy controls.

Gross cystic disease fluid protein-15 (GCDFP-15), also known as prolactin inducible protein (PIP), is a secretory glycoprotein in human tear fluids. Priyadarsini et $\mathrm{al}^{37}$ reported that the intensity of GCDFP-15/PIP was significantly higher in control group compared with $\mathrm{KC}$ patients using both in vivo and in vitro systems. They defined GCDFP-15/PIP as a potential biomarker for KC.

Karamichos et $\mathrm{al}^{38}$ have investigated the tear metabolite changes in KC. They have identified a total of 296 different metabolites of which $>40$ were significantly regulated between three groups (healthy controls, KC patients using RGP lenses, KC with no correction). The levels of metabolites related to citric acid cycle, urea cycle, and oxidative stress have shown significant alterations in KC patients' tears compared with healthy controls.

Oxidative stress is reported as a part of KC pathophysiology. Tear fluid antioxidants cysteine, ascorbic acid, glutathione, uric acid and tyrosine were analyzed.

In between the five antioxidants, tyrosine and glutathione showed significant decrease, while tyrosine and uric acid showed significant increase in $\mathrm{KC}$ compared with the healthy controls. ${ }^{39}$

\section{CONCLUSION}

Tear fluid is an accessible source that contains numerous proteins and metabolites. Many inflammatory components have been detected in the tear analysis while trying to identify KC pathogenesis. Published data about tear components' changes of $\mathrm{KC}$ patients are limited and quite variable (Table 1). It has been shown that some cytokine levels in the tear are similarly altered in other ocular disorders. Despite large numbers of studies, a sensitive and specific marker in tear for $\mathrm{KC}$ has not been found yet. Using multiple biomarkers together instead of one can give more accurate results for diagnosis.
Table 1: Summary of tear biomarkers in KC

\begin{tabular}{|c|c|c|c|}
\hline Reference & $\begin{array}{l}\text { Analysis } \\
\text { techniques }\end{array}$ & Biomarkers & Expression \\
\hline \multirow[t]{3}{*}{ Lema et $\mathrm{al}^{25}$} & \multirow[t]{3}{*}{ ELISA } & IL-6 & $\uparrow$ \\
\hline & & TNF- $\alpha$ & $\uparrow$ \\
\hline & & MMP-9 & $\uparrow$ \\
\hline \multirow[t]{4}{*}{ Lema et $\mathrm{al}^{26}$} & \multirow[t]{4}{*}{ ELISA } & IL-6 & $\uparrow$ \\
\hline & & TNF- $\alpha$ & $\uparrow$ \\
\hline & & ICAM-1 & $\uparrow$ \\
\hline & & VCAM-1 & $\uparrow$ \\
\hline \multirow{4}{*}{$\begin{array}{l}\text { Pannebaker et } \mathrm{al}^{27} \\
\text { Jun et } \mathrm{al}^{28}\end{array}$} & LCMS & MMP-1 & $\uparrow$ \\
\hline & \multirow{3}{*}{$\begin{array}{l}\text { Multiplex } \\
\text { immune-bead } \\
\text { assay }\end{array}$} & IL-12 & $\downarrow$ \\
\hline & & TNF- $\alpha$ & $\downarrow$ \\
\hline & & CCL5 & $\downarrow$ \\
\hline \multirow[t]{5}{*}{ Acera et $\mathrm{al}^{30}$} & \multirow[t]{5}{*}{ 2-DE/LCMS } & Cystatins & $\downarrow$ \\
\hline & & Lipocalin-1 & $\uparrow$ \\
\hline & & Lipophilin & $\downarrow$ \\
\hline & & $\begin{array}{l}\text { Phospholipase } \\
\text { A2 }\end{array}$ & $\downarrow$ \\
\hline & & Albumin & $\uparrow$ \\
\hline \multirow{2}{*}{$\begin{array}{l}\text { Balasubramanian } \\
\text { et } \mathrm{al}^{31}\end{array}$} & \multirow[t]{2}{*}{ ELISA } & Lactoferrin & $\downarrow$ \\
\hline & & $\operatorname{sig} A$ & $\downarrow$ \\
\hline You et $\mathrm{al}^{33}$ & ELISA & SFRP-1 & $\downarrow$ \\
\hline \multirow{3}{*}{$\begin{array}{l}\text { Balasubramanian } \\
\text { et } \mathrm{al}^{34}\end{array}$} & \multirow{3}{*}{$\begin{array}{l}\text { Specific } \\
\text { antibody array }\end{array}$} & MMP-1,3,7,13 & $\uparrow$ \\
\hline & & IL-4,5,6,8 & $\uparrow$ \\
\hline & & TNF- $\alpha, \beta$ & $\uparrow$ \\
\hline \multirow[t]{3}{*}{ Sorkhabi et $\mathrm{al}^{35}$} & \multirow[t]{3}{*}{ ELISA } & IL-6,1b & $\uparrow$ \\
\hline & & IL-10 & $\downarrow$ \\
\hline & & IFN- $\gamma$ & $\uparrow$ \\
\hline Shetty et $\mathrm{al}^{36}$ & ELISA & LOX & $\downarrow$ \\
\hline $\begin{array}{l}\text { Priyadarsini } \\
\text { et } \mathrm{al}^{37}\end{array}$ & LCMS & $\begin{array}{l}\text { GCDFP-15/ } \\
\text { PIP }\end{array}$ & $\downarrow$ \\
\hline
\end{tabular}

LCMS: Liquid chromatography-mass spectrometry; 2-DE: Twodimensional gel electrophoresis

\section{REFERENCES}

1. Rabinowitz YS. Keratoconus. Surv Ophthalmol 1998 JanFeb;42(4):297-319.

2. Kennedy RH, Bourne WM, Dyer JA. A 48-year clinical and epidemiologic study of keratoconus. Am J Ophthalmol 1986 Mar;101(3):267-273.

3. Galvis V, Sherwin T, Tello A, Merayo J, Barrera R, Acera A. Keratoconus: an inflammatory disorder? Eye (Lond) 2015 Jul;29(7):843-859.

4. Ohashi Y, Dogru M, Tsubota K. Laboratory findings in tear fluid analysis. Clin Chim Acta 2006 Jul;369(1):17-28.

5. Rantamäki AH, Seppänen-Laakso T, Oresic M, Jauhiainen M, Holopainen JM. Human tear fluid lipidome: from composition to function. PLoS One 2011 May;6(5):e19553.

6. Chen L, Zhou L, Chan EC, Neo J, Beuerman RW. Characterization of the human tear metabolome by LC-MS/MS. J Proteome Res 2011 Oct;10(10):4876-4882.

7. Zhou L, Zhao SZ,Koh SK,Chen L, Vaz C, Tanavde V, Li XR, Beuerman RW. In-depth analysis of the human tear proteome. J. Proteomics 2012 Jul;75(13):3877-3885.

8. Zhou L, Beuermanm RW. Tear analysis in ocular surface diseases. Prog Retin Eye Res 2012 Nov;31(6):527-550. 
9. Green-Church KB, Nichols KK, Kleinholz NM, Zhang L, Nichols JJ. Investigation of the human tear film proteome using multiple proteomic approaches. Mol Vis 2008 Mar;14: 456-470.

10. Funke S, Azimi D, Wolters D, Grus FH, Pfeiffer N. Longitudinal analysis of taurine induced effects on the tear proteome of contact lens wearers and dry eye patients using a RP-RP-Capillary-HPLC-MALDI TOF/TOF MS approach. J Proteomics 2012 Jun;75(11):3177-3190.

11. Biomarkers Definitions Working Group. Biomarkers and surrogate endpoints: preferred definitions an conceptual framework. Clin Pharmacol Ther 2001 Mar;69(3):89-95.

12. Posa A, Bräuer L, Schicht M, Garreis F, Beileke S, Paulsen F. Schirmer strip vs. capillary tubemethod: non-invasive methods of obtaining proteins from tear fluid. Ann Anat 2013 Mar; 195(2):137-142.

13. Sitaramamma T, Shivaji S, Rao GN. Effect of storage on protein concentration of tear samples. Curr Eye Res 1998 Oct;17(10):1027-1035.

14. Herber S, Grus FH, Sabuncuo P, Augustin AJ. Changes in the tear protein patterns of diabetic patients using twodimensional electrophoresis. Adv Exp Med Biol 2002 Jan; 506(Pt A):623-626.

15. Tomosugi N, Kitagawa K, Takahashi N, Sugai S, Ishikawa I. Diagnostic potential of tear proteomic patterns in Sjogren's syndrome. J Proteome Res 2005 May-Jun;4(3):820-825.

16. Wong TT, Zhou L, Li J, Tong L, Zhao SZ, Li XR, Yu SJ, Koh SK, Beuerman RW. Proteomic profiling of inflammatory signaling molecules in the tears of patients on chronic glaucoma medication. Invest Ophthalmol Vis Sci 2011 Sep;52(10): 7385-7391.

17. Grus FH, Boehm N, BeckS, Schlich M, Lossbrandt U, Pfeiffer N. Autoantibody profiles in tear fluid as a diagnostic tool in glaucoma. Invest Ophthalmol Vis Sci 2010 Apr;51:6110.

18. Boehm N, Funke S, Wiegand M, Wehrwein N, Pfeiffer N, Grus FH. Alterations in the tear proteome of dry eye patients-a matter of the clinical phenotype. Invest Ophthalmol Vis Sci 2013 Mar;54(3):2385-2392.

19. Grus FH, Boehm N, Berneiser S, Lamparter J, Wiegand M, Wiegel N, Pfeiffer N. Analysis of tear protein profiles in dry-eye patients by mass spectrometry. Invest Ophthalmol Vis Sci 2009 Apr;50:2546.

20. Matheis N, Okrojek R, Grus FH, Kahaly GJ. Proteomics of tear fluid in thyroid-associated orbitopathy. Thyroid 2012 Oct;22(10):1039-1045.

21. Massingale ML, Li X, Vallabhajosyula M, Chen D, Wei $Y$, Asbell PA. Analysis of inflammatory cytokines in the tears of dry eye patients. Cornea 2009 Oct;28(9):1023-1027.

22. Collier SA. Is the corneal degradation in keratoconus caused by matrix-metalloproteinases? Clin Exp Ophthalmol 2001 Dec;29(6):340-344.

23. Abalain JH, Dossou H, Colin J, Floch HH. Levels of collagen degradation products (telopeptides) in the tear film of patients with keratoconus. Cornea 2000 Jul;19(4):474-476.
24. Fini ME, CookJR, Mohan R. Proteolytic mechanisms in corneal ulceration and repair. Arch Dermatol Res 1998 Jul;290(Suppl): S12-S23.

25. Lema I, Durán JA. Inflammatory molecules in the tears of patients with keratoconus. Ophthalmology 2005 Apr;112(4) 654-659.

26. Lema I, Durán JA, Ruiz C, Díez-Feijoo E, Acera A, Merayo J. Inflammatory response to contact lenses in patients with keratoconus compared with myopic subjects. Cornea 2008 Aug;27(7):758-763

27. Pannebaker C, Chandler HL, Nichols JJ. Tear proteomics in keratoconus. Mol Vis 2010 Oct;16:1949-1957.

28. Jun AS, Cope L, Speck C, Feng X, Lee S, Meng H, Hamad A, Chakravarti S. Subnormal cytokine profile in the tear fluid of keratoconus patients. Plos One 2011 Jan;6(1):e16437.

29. Lema I, Sobrino T, Durán JA, Brea D, Díez-Feijoo E. Subclinical keratoconus and inflammatory molecules from tears. $\mathrm{Br}$ J Ophthalmol 2009 Jun;93(6):820-824.

30. Acera A, Vecino E, Rodriguez-Agirretxe I, Aloria K, Arizmendi JM, Morales C, Duran JA. Changes in tear protein profile in keratoconus disease. Eye (Lond) 2011 Sep;25(9):1225-1233.

31. Balasubramanian SA, Pye DC, Willcox MD. Levels of lactoferrin, secretory $\operatorname{IgA}$ and serum albumin in the tear film of people with keratoconus. Exp Eye Res 2012 Mar;96(1):132-137.

32. Fust A, Veres A, Kiszel P, Nagy ZZ, Cervenak L, Csakany B, Maka E, Suveges I,Grus FH. Changes in tear protein pattern after photorefractive keratectomy. Eur J Ophthalmol 2003 Jul;13(6):525-531.

33. You J, Hodge C, Wen L, McAvoy JW, Madigan MC, Sutton G. Tear levels of SFRP1 are significantly reduced in keratoconus patients. Mol Vis 2013 Feb;19:509-515.

34. Balasubramanian SA, Mohan S, Pye DC, Willcox MD. Proteases, proteolysis and inflammatory molecules in the tears of people with keratoconus. Acta Ophthalmol 2012 Jun;90(4):e303-e309.

35. Sorkhabi R, Ghorbanihaghjo A,Taheri N, Ahoor MH. Tear film inflammatory mediators in patients with keratoconus. Int Ophthalmol 2015 Aug;35(4):467-472.

36. Shetty R, Sathyanarayanamoorthy A, Ramachandra RA, Arora V, Ghosh A, Srivatsa PR, Pahuja N, Nuijts RM, Sinha-Roy A, Mohan RR, et al. Attenuation of lysyl oxidase and collagen gene expression in keratoconus patient corneal epithelium corresponds to disease severity. Mol Vis 2015 Jan;21:12-25.

37. Priyadarsini S, Hjortdal J, Sarker-Nag A, Sejersen H, Asara JM, Karamichos D. Gross cystic disease fluid protein-15/ prolactin-inducible protein as a biomarker for keratoconus disease. PLoS One 2014 Nov;9(11):e113310.

38. Karamichos D, Zieske JD, Sejersen H, Sarker-Nag A, Asara JM, Hjortdal J. Tear metabolite changes in keratoconus. Exp Eye Res 2015 Mar;132:1-8.

39. Saijyothi AV, Fowjana J, Madhumathi S, Rajeshwari M, Thennarasu M, Prema P, Angayarkanni N. Tear fluid small molecular antioxidants profiling shows lowered glutathione in keratoconus. Exp Eye Res 2012 Oct;103:41-46. 